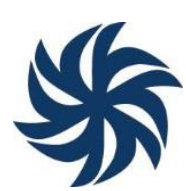

\title{
DO DIREITO FLORESTAL AO DIREITO AMBIENTAL: UM RESGATE HISTÓRICO DA PROTEÇÃO JURÍDICA DO MEIO AMBIENTE
}

\section{FROM FOREST RIGHT TO ENVIRONMENTAL RIGHT: A HISTORICAL RESCUE OF JURIDICAL PROTECTION OF THE ENVIRONMENT}

\section{DE LA LEY FORESTAL A LA LEY AMBIENTAL: UNA RECUPERACIÓN HISTÓRICA DE LA PROTECCIÓN LEGAL AMBIENTAL}

\author{
Pablo Alan Jenison Silva* \\ Cintia Garabini Lages**
}

Resumo: A proteção do Meio ambiente e a compreensão de sua função para manutenção da vida são imprescindíveis para a efetivação do projeto constitucional de fortalecimento do Estado de Direito Socioambiental. Com o objetivo de contribuir para um melhor entendimento desses aspectos o presente artigo aborda a evolução da proteção jurídica ambiental, demonstrando a origem histórica do Direito Florestal a partir de uma breve perspectiva comparada e reconstrói o desenvolvimento deste no ordenamento jurídico brasileiro, além de apresentar a mudança de paradigmas ocorrida com a inclusão de novos objetos de proteção dando origem ao Direito ambiental e dessa forma redefinindo a concepção de Estado a partir do reconhecimento de novos direitos e reinterpretação dos direitos anteriormente reconhecidos. Para tanto, utilizou-se da dogmática jurídica, sobretudo, da revisão da literatura e da legislação brasileira.

Palavras-chave: Meio Ambiente; Direito Florestal; Direito Ambiental; Ecologização Constitucional; Legislação Ambiental.

Abstract: The protection of the environment and the comprehension of its function for the maintenance of life are indispensable for the realization of the constitutional project of strengthening of the State of Social Environmental Right. The aim of this article is to contribute to a better understanding of the aspects involved in this issue, this paper deals with the development of environmental legal protection, demonstrating the historical origin of Forest Right from a brief comparative perspective and reconstructing its development in the planning Brazilian law, besides presenting the paradigm shift that occurred with the inclusion of new objects of protection giving rise to Environmental Right and thereby

\footnotetext{
*Mestrando em Direito no Programa de Pós Graduação em Direitos Sociais da Universidade Federal de Pelotas - UFPel. ORCID: https://orcid.org/0000-0002-3799-8551

** Doutora e Mestre em Direito pela Pontifícia Universidade Católica de Minas Gerais. Professora do Programa de Pósgraduação stricto sensu da Universidade de Itaúna. Professora de Direito Constitucional e Hermenêutica e Argumentação Jurídica da Pontifícia Universidade Católica de Minas Gerais. Coordenadora de Pesquisa da Faculdade Mineira de Direito em Betim. E-mail: cintiagarabini@gmail.com
} 
redefining the concept of State from the recognition of new rights and reinterpretation of previously recognized rights. For this purpose, it was used of legal dogmatic, the review of Brazilian literature and legislation.

Keywords: Environment; Forest Right; Environmental Right; Constitutional greening; Environmental legislation.

Resumen: La protección del medio ambiente y la comprensión de su función para mantener la vida son esenciales para la realización del proyecto constitucional de fortalecimiento del estado de derecho social y ambiental. Con el fin de contribuir a una mejor comprensión de estos aspectos, este artículo analiza la evolución de la protección legal del medio ambiente, demuestra el origen histórico de la Ley Forestal desde una breve perspectiva comparativa y reconstruye su desarrollo en el sistema legal brasileño. El cambio de paradigma se produjo con la inclusión de nuevos objetos de protección que dieron lugar a la ley ambiental y, por lo tanto, redefinieron la concepción del estado a partir del reconocimiento de nuevos derechos y la reinterpretación de derechos previamente reconocidos. Para eso, utilizamos la dogmática legal, sobre todo, la revisión de la literatura y la legislación brasileña.

Palabras clave: Medio Ambiente; Ley Forestal; Derecho Ambiental; Ecologización Constitucional; Legislación Ambiental.

\section{Introdução}

A sociedade está em constante mudança e o Direito, para atender às necessidades desta, tende a transformar-se, caracterizando-se como essencialmente mutável. A complexidade dos problemas ambientais na contemporaneidade aponta a necessidade de desenvolvimento de novas medidas protetivas do meio ambiente essenciais e urgentes, medidas essas que se revestem de juridicidade na medida em que visam a garantia de direitos fundamentais constitucionalmente tutelados.

No Brasil, o movimento ecologista da década de 1970 inaugurou um novo momento na história da tutela do meio ambiente, promovendo mudanças paradigmáticas no que se refere ao alcance da proteção ambiental e exercendo influência direta no processo constituinte, possibilitando ao mesmo tempo o reconhecimento do direito ao meio ambiente sadio como direito fundamental e a introdução de um capítulo sobre o Meio Ambiente no Título reservado à Ordem Social na Constituição Federal de 1988.

Nesse sentido, o presente trabalho questiona como é possível a construção da proteção jurídico-constitucional do Meio Ambiente em um modelo de desenvolvimento apto a considerar as gerações futuras e a sustentabilidade dos recursos naturais. A reposta provisória a este questionamento encontra-se na delimitação de um novo paradigma de estado, o Estado de Direito Ambiental. 
Para tanto, inicialmente demonstrar-se-á a origem histórica do Direito Florestal a partir de uma breve perspectiva comparada, bem como será reconstruído seu desenvolvimento no ordenamento jurídico brasileiro, além de demonstrar a mudança de paradigmas ocorrida com a inclusão de novos direitos objetos de proteção jurídico-constitucional, dando origem ao Direito Ambiental e dessa forma redefinindo a concepção de Estado a partir do reconhecimento de novos direitos e reinterpretação dos direitos anteriormente reconhecidos.

\section{Breves comentários ao paradigma do direito florestal no direito comparado}

O Direito Comparado oferece meios para melhor compreensão do processo da construção do Direito por via da atividade legislativa, de modo que para a concepção adequada do objeto de estudo do presente trabalho, faz-se imprescindível a sua contextualização histórica e espacial. Assim, verificar-se-á, sumariamente, nesta sequência, a origem da proteção jurídica das florestas em diferentes países.

De acordo com Pereira (1950) a história do Direito Florestal se condensa com a história econômica da madeira, sua abundância e crise, demonstrando que as preocupações com as florestas iniciaram quando os povos começaram a sentir as consequências de sua falta, refletidas nos efeitos climáticos, na agricultura e no desaparecimento de matéria prima para as necessidades da sociedade industrial.

Segundo o autor, a origem do Direito Florestal está intimamente conexa com a importância física das florestas e a proteção jurídica dispensada às árvores em todas as civilizações desde a Antiguidade, com as referências à veneração religiosa que se fazia à floresta e nos sacrifícios aos deuses em todos os pontos da terra, estabelecendo sanções em favor de sua proteção. (PEREIRA, 1950, p. 17).

Alude o referido autor que a proteção florestal na Grécia Antiga estava restrita ao incêndio, considerado delito criminal passível de punição. Registra também recomendações imperiais de várias dinastias chinesas na difusão da silvicultura tornando este país referência no estudo, análise e desenvolvimento do conhecimento científico desta, assim como o Japão, que instituiu quatro escolas superiores de silvicultura, conferindo relevo internacional à matéria.

A Lei das XII Tábuas, em 450 a. C apresentava disposições para prevenir a devastação das florestas. Segundo Venosa (2016, p. 30), "Se alguém, sem razão, cortou árvores de outrem, que seja condenado a indenizar à razão de 25 asses por árvore cortada", abrindo caminhos à construção da proteção florestal em Roma, que também dispunha de uma lei contra incendiários, a exemplo do Direito Italiano medieval, onde o incêndio nas florestas era considerado um delito gravíssimo.

No Direito francês, as variadas legislações comprovam a especial preocupação protecionista aos recursos florestais, estabelecendo penas rigorosas como punição corporal nos 
crimes de incêndio, influenciados pelo Direito Germânico, que na Idade Média, punia com pena de morte os incendiários, modelo adotado também pelo Código Penal Austríaco (PEREIRA, 1950). Assim, ao longo da História, observa-se que a se floresta tornou objeto de proteção jurídica, pelos mais variados povos, sempre pelo viés punitivo penal. Entretanto, com o crescimento da população, o desenvolvimento da sociedade e consequente valorização dos recursos florestais, fundamentais para a economia, a proteção florestal restrita à esfera penal restou insuficiente. Diante deste cenário, Osny Duarte Pereira expôs:

Compreendeu-se que não bastava castigar a destruição. Eram necessárias disposições coercitivas destinadas a aplicar meios de conservar e de desenvolver essa riqueza natural, indispensável à manutenção da vida nos aglomerados urbanos e à própria sobrevivência da humanidade, afastando o perigo na fome, das secas, das inundações, da variedade climática e outros danos conhecidamente ligados a devastação da selva (PEREIRA, 1950, p. 15).

Surgem legislações voltadas para a utilização racional da terra, determinando normas no sentido de promover o melhor aproveitamento desta, lançando-se mão de novas técnicas oriundas da evolução das ciências biológicas e ecologia, que conjuntamente com a silvicultura estabeleceram formas de extrativismo que garantisse a manutenção da fertilidade e a estabilização dos recursos florestais.

Tais técnicas tornaram-se complexas em virtude do desconhecimento destas ciências por parte dos seus destinatários, o que levou o Estado a reconhecer a necessidade de estabelecer um departamento administrativo especializado que auxiliasse a população na implementação deste novo modelo de cultivo, bem como responsável pela produção de uma legislação florestal codificada.

É importante salientar que o conteúdo desses diplomas legais não foi instituído de forma uniforme e que estes receberam influência direta da política econômica de cada país. Essa intervenção estatal variou de acordo os paradigmas de suas respectivas constituições, adotando tendências individualistas ou socialistas na regulamentação da exploração, conservação e reprodução dos recursos florestais, inclusive em terras particulares (AHRENS, 2003).

$\mathrm{Na}$ Inglaterra, a Magna Carta de 1215 ampliou os direitos da nobreza sobre as florestas. Na França, a criação de tribunais florestais contribuiu para o surgimento de leis florestais mais específicas como a promulgação da Ordonnance dês Eaux et Forêts ${ }^{l}$ em 1669 pelo Ministro JeanBaptiste Colbert (DUBY, 1993). Embora tenha ocorrido a continuidade no desenvolvimento de outras legislações internacionais acerca da proteção às florestas, cumpre destacar que nesse

\footnotetext{
${ }^{1}$ A Ordenação de Luís XVI conhecida como Portaria de 1669, surgiu da preocupação de Jean-Baptiste Colbertcom a escassez de madeiras no Reino para a construção de embarcações. Assim, Luís XIV promulgou uma ordem de reforma nas Águas e Florestas com o objetivo de controlar o acesso dos súditos aos recursos naturais, unificar leis florestais, reorganizar a administração, especificar as competências dos oficiais reais, além de impor a todo o reino um modo de exploração uniforme das florestas. É por essa razão que a Portaria de 1669 é às vezes considerada o primeiro Código florestal (CARNEIRO, 2011)
} 
ínterim o Brasil já apresentava forte expressão no cenário de exploração da madeira, como será perscrutado a seguir.

\section{Evolução histórica do Direito Florestal no Brasil}

A relevância dispensada ao Meio Ambiente evoluiu no transcorrer dos séculos, de maneira que somente recentemente concebeu-se este como indispensável para a manutenção da vida. Inicialmente, legitimava-se o antropocentrismo, estatuindo o ser humano como o centro de tudo, a medida de todas as coisas, e neste contexto não era conferida grande importância para o meio ambiente em si, objeto de exploração humana como se não houvessem limites a serem respeitados. Embora os primeiros regramentos acerca da proteção das florestas pelos mais variados povos tenham sua gênese na Antiguidade, atualmente o termo Direito Florestal é incomum no meio jurídico, apesar de ser o embrião do Direito Ambiental, que somente passou a ter expressão na segunda metade do século XX.

No Brasil, a adoção de regramentos de cunho protecionista acerca das florestas advém do período colonial brasileiro, quando a Coroa Portuguesa começou a restringir o direito de propriedade das mesmas. Desde então, várias leis foram criadas como forma de intervir na forma como o homem explora o meio ambiente envolvendo questões ecológicas, políticas e econômicas.

Para uma melhor compreensão faz-se necessária a reconstrução dos marcos substanciais de sua evolução, estabelecendo-se de forma lacônica um diálogo histórico indicando seus avanços e retrocessos.

\subsection{Período Colonial}

Em Portugal, a construção do Direito Florestal seguiu características das normas observadas no mundo inteiro, prescrevendo inicialmente matérias relacionadas aos casos de incêndio. Contudo, com o desenvolvimento comercial da madeira, principalmente do pau-brasil, os colonizadores portugueses ampliaram o regime de regulação do patrimônio florestal, demonstrando desde então, que as florestas eram consideradas importantes ativos econômicos e por isso a necessidade de estabelecê-la como objeto de proteção jurisdicional em terrae brasilis, não com o intuito da preservação, mas como bem de valor de interesse exclusivo do poder público, tratava-se do "Regimento do Pau Brasil" (PEREIRA, 1950).

Quando da descoberta do Brasil, vigoravam em Portugal as Ordenações Afonsinas promulgadas em 1446, por Dom Afonso V, consideradas o primeiro Código completo de legislação a aparecer na Europa depois da Idade Média, sendo substituída posteriormente pelas Ordenações Manuelinas, editadas em 1514 e promulgadas em 1521 (MAGALHÃES, 2002).

Em 1530, a Coroa lusitana instituiu as capitanias hereditárias no Brasil como medida de combate ao contrabando de madeiras comum à época e à manutenção da extensão territorial da 
colônia. Assim, protegiam-se os recursos naturais por força de ordem econômica, em razão do alto consumo de madeira como combustível e outras utilidades, além de favorecer a ocupação sistemática do Brasil.

De acordo com Dean (2006), no período colonial a escassez de madeira nos estaleiros reais de Lisboa, levou a Coroa Portuguesa a expedir ordens reais em 1698, que limitando o direito privado dos capitães donatários de explorar e negociar a madeira extraída no território brasileiro favoreceu o interesse central dos portugueses, atitude essencial à defesa do Império e ao aumento de seu comércio. Assim, a Coroa declarava toda a madeira naval como "madeira da lei", ou seja, de sua propriedade, instituindo inclusive as chamadas "Áreas de Reserva naval”.

No mesmo sentido, Pereira (1950) afirma que em 11 de junho de 1799, o Desembargador Francisco Nunes da Costa, que exercia o cargo de "Inspetor dos Reais Cortes" estabeleceu o primeiro regimento de cortes de madeiras no Brasil. Esse diploma estabeleceu rigorosas regras para a derrubada de árvores, além de outras restrições e foi robustecido com as instruções de José Bonifácio em 1802, que determinaram o reflorestamento da costa brasileira.

A preocupação jurídica com as florestas, iniciada a partir da colonização brasileira, foi estabelecida pela coroa portuguesa, com vistas às necessidades metropolitanas para consolidar o império colonial, ao mesmo passo que a política construída ao longo dos ciclos econômicos de desenvolvimento, sempre persistiu numa articulação de caráter elitista, patrimonialista e voltada especificamente para a acumulação do capital, executada sem qualquer cuidado ou preocupação com os recursos florestais, numa inexorável busca pelo desenvolvimento.

Dessa forma, o modelo colonial promoveu uma economia destrutiva e improdutiva, comprometendo o regime de grandes concessões de terra promovido pelas sesmarias que chegou ao Império enfraquecido, gerando instabilidade política e favorecendo o enfraquecimento da proteção florestal.

\subsection{Período Imperial}

O período imperial brasileiro foi marcado pelo fim do regime sesmarial em 17 de julho de 1822 e contribuiu de forma significativa para o monopólio estatal do comércio de madeira, motivado pela valorização da exportação do pau-brasil. Houve, nesse contexto, a promulgação do Código Criminal de 1830 que tipificou como crime o corte ilegal de madeira. Em 1886, a promulgação da Lei $n^{\circ}$. 3.311 estabeleceu o incêndio como um crime especial. Assim, ficou evidente que a proteção das florestas estava restrita ao âmbito penal.

A Constituição Imperial do Brasil em 1824 foi silente em matéria ambiental e manteve a concepção clássica da propriedade como um direito geral, de caráter perpétuo, usufruído independentemente do modo de exercício desse direito, caracterizando um modelo evidentemente liberal, conforme se observa em seu artigo 179, XXII: 


\begin{abstract}
A inviolabilidade dos Direitos Civis, e Politicos dos Cidadãos Brazileiros, que tem por base a liberdade, a segurança individual, e a propriedade, é garantida pela Constituição do Imperio, pela maneira seguinte:

(...)

XXII - É garantido o Direito de Propriedade em toda a sua plenitude. Se o bem publico legalmente verificado exigir o uso e emprego da Propriedade do Cidadão, será ele previamente indemnisado do valor della. A Lei marcará os casos, em que terá logar esta única excepção, e dará as regras para se determinar a indemnização. (BRASIL, 1824)
\end{abstract}

No decurso do período imperial foram editados também dois novos diplomas legais: a Lei 601, de 1850 que introduziu inovações ecológicas relevantes, pois instituiu o princípio da responsabilidade por dano ambiental, estabelecendo para o infrator, sanções administrativa, penal e civil, e o Decreto n. 4.887, de 5 de fevereiro de 1872, que exigia licença do governo para qualquer exploração florestal, estabelecendo a primeira empresa especializada no corte de madeira, a Companhia Florestal Paranaense (MAGALHÃES, 2002). Neste período importantes avanços em matéria ambiental foram alcançados tornando-se objeto de debate durante a República como será visto a seguir.

\title{
3.3 Período Republicano
}

Em meio à turbulência política oriunda da abolição da escravatura, a proteção florestal e de seus recursos recebeu significativo impulso na fase republicana, apresentando segundo Magalhães (2002), três períodos claramente delimitados: a) período de evolução do Direito Ambiental, de 1889 a 1981; b) período de consolidação do Direito Ambiental, de 1981 a 1988 e c) período de aperfeiçoamento de Direito Ambiental, a partir de 1988. Apesar do avanço de edições de diplomas legais até o final do período imperial, a primeira Constituição República foi omissa em relação aos avanços já conquistados em matéria florestal:

\footnotetext{
A Constituição de 24 de fevereiro de 1891 não contém nenhuma palavra sobre árvore. Limitou-se a dizer, no art. 34 - Compete privativamente ao Congresso Nacional: 29. Legislar sobre terras e minas de propriedade da União. No art. 35 - Incumbe, outrossim, ao Congresso, mas não privativamente: 2. Animar, no país, o desenvolvimento das letras, artes e ciências, bem como a imigração, a agricultura, a indústria e o comércio, sem privilégios que tolham a ação dos governos locais (PEREIRA, 1950, p.107)
}

Além disso, a Constituição Brasileira de 1891 consolidou o direito ilimitado sobre a propriedade, legitimando os poderes de usar (ius utendi), fruir (ius fruendi) e abusar (ius abutendi) de forma indiscriminada. Assim, os recursos naturais passaram a figurar como objeto de direito do seu titular e ficavam sob total arbítrio deste, o que acarretou crescimento nos níveis de desmatamento do país (BRASIL, 1891). 
Por meio do Decreto 8.843, de 26 de junho de 1911, estabeleceu-se no então Território do Acre, a primeira Reserva florestal do Brasil, (embora não tenha sido implementada), assim como, registrou-se a primeira tentativa de elaboração de um Código Florestal, que não se concretizou, demonstrando a retomada da preocupação com as matas nacionais.

Em 1921, foi criado o Serviço Florestal do Brasil² cujo objetivo residia na conservação e o aproveitamento das florestas, regulamentado pelo Departamento de Recursos Naturais Renováveis $^{3}$ e este substituído posteriormente pelo Instituto Brasileiro de Desenvolvimento Florestal $^{4}$, sucedido pelo IBAMA - Instituto Brasileiro de Meio Ambiente e dos Recursos Renováveis 5 .

A Constituição Federal de 1934 introduziu mudanças em matéria de proteção ambiental e redefiniu o sistema de repartição de competências em relação à União e aos Estados:

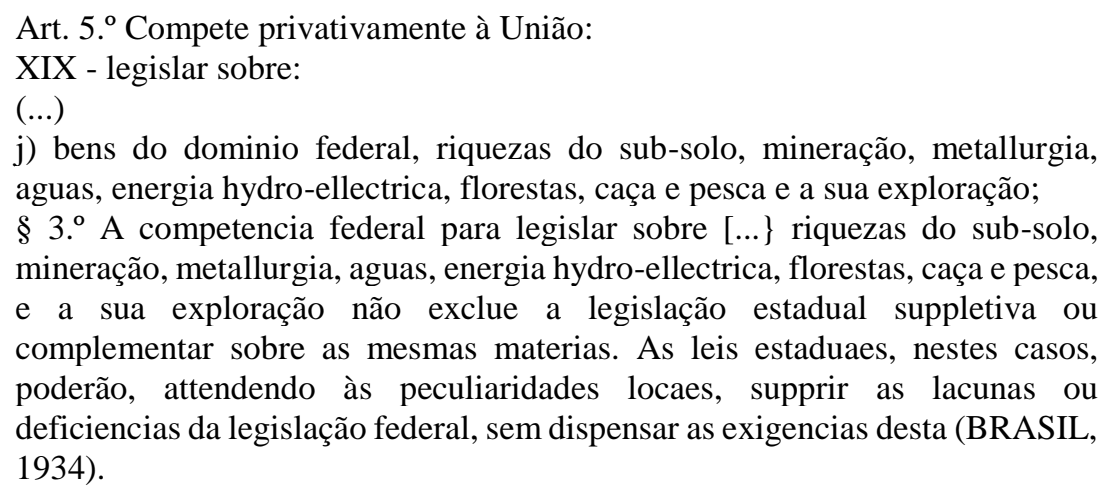

No mesmo ano entraram em vigor o Código Florestal, instituído pelo Decreto n ${ }^{\circ} 23.793$, de 10 de julho de 1934 e o Código de Águas, Decreto nº 24.643, além da realização da I Conferência Brasileira para a proteção da Natureza. (MAGALHÃES, 2002).

A Constituição Federal de 1937 representou um retrocesso em relação à Constituição anterior uma vez que apenas assegurou o direito à propriedade, e fazendo vaga referência que seu conteúdo e limites seriam definidos nas leis que regulassem o seu exercício: "o direito de propriedade, salvo a desapropriação por necessidade ou utilidade pública, mediante indenização prévia. O seu conteúdo e os seus limites serão os definidos nas leis que lhe regularem o exercício". (BRASIL, 1937).

Em contrapartida, a Constituição Federal de 1946 representou um marco jurídico na proteção ambiental, pois estabeleceu a desapropriação por interesse social e, sobretudo no sentido de assegurar a justa distribuição e igual oportunidade de acesso à propriedade, conforme pode se

\footnotetext{
${ }^{2}$ Decreto 4.421/1921 - Cria o Serviço Florestal do Brasil (BRASIL, 1921)

${ }^{3}$ Decreto 17.042/1925 - Dá regulamento ao Serviço Florestal do Brasil. (BRASIL, 1925)

${ }^{4}$ Decreto 289/1967 - Cria o Instituto Brasileiro do Desenvolvimento Florestal e dá outras providências (BRASIL, 1967b).

${ }^{5}$ Lei no 7.735/ 1989 - Dispõe sobre a extinção de órgão e de entidade autárquica, cria o Instituto Brasileiro do Meio Ambiente e dos Recursos Naturais Renováveis e dá outras providências (BRASIL, 1989).
} 
extrair explicitamente do seu artigo 147: "o uso da propriedade será condicionado ao bem-estar social. A Lei poderá, com observância do disposto no artigo $141^{6}$, parágrafo $16^{7}$, promover a justa distribuição da propriedade, com igual oportunidade para todos" (BRASIL, 1946).

Referida Constituição atribuiu à União competência para legislar sobre florestas, além das riquezas do subsolo mineração, água, entre outros. Introduziu ainda a desapropriação por interesse social em Áreas de Reserva florestal, regulamentado pela Lei 4.132/62, promovendo avanços na proteção ambiental e contribuindo para o desenvolvimento da consciência conservacionista que se observou mundialmente.

Nesse cenário, o Código Florestal de 1965, Lei 4.778, de 22 de setembro de 1965, substituiu o Código de 1934, e em 1967, foi estabelecida a Política Nacional de Saneamento Básico pelo Decreto no 248 , de 28 de fevereiro de 1967, contendo diretrizes para adoção de programas governamentais no combate à poluição. Nesta mesma data foi editado o Decreto 289, criando o Instituto Brasileiro de Desenvolvimento Florestal.

Em que pese o desenvolvimento progressivo observado nesse período no tocante à proteção jurídica ao meio ambiente, a Constituição de 1967 preservou as mesmas disposições da Constituição anterior em seus artigos $8^{\circ}$, XVII, h e 172, parágrafo único, os quais prescrevem que "compete à União: [...] XVII - legislar sobre: [...] h) jazidas, minas e outros recursos minerais; metalurgia; florestas, caça e pesca" e, que "ficam sob a proteção especial do Poder Público os documentos, as obras e os locais de valor histórico ou artístico, os monumentos e as paisagens naturais notáveis, bem como as jazidas arqueológicas" (BRASIL, 1967a).

Lado outro, a Emenda Constitucional no. 01, de 17 de outubro de 1969 manteve a defesa do patrimônio histórico, cultural e paisagístico bem como disposições acerca de regras de competência oriundas da Constituição antecessora, consoante demostrado em seu artigo 172, segundo o qual “a lei regulará, mediante prévio levantamento ecológico, o aproveitamento agrícola de terras sujeitas a intempéries e calamidades. O mau uso da terra impedirá o proprietário de receber incentivos e auxílios do Governo" (BRASIL, 1969).

A elaboração do I Plano Nacional de Desenvolvimento, aprovado em 4 de novembro de 1971, pela Lei 5.727 significou verdadeiro retrocesso, pois com a introdução do Programa de Interação Nacional $(\mathrm{PIN})^{8}$ e o Programa de Redistribuição de Terras e de Estímulos à Agropecuária do Norte e Nordeste (PROTERRA) ${ }^{9}$, houve acentuado desmatamento por parte do

\footnotetext{
${ }^{6}$ Art 141 - A Constituição assegura aos brasileiros e aos estrangeiros residentes no País a inviolabilidade dos direitos concernentes à vida, à liberdade, a segurança individual e à propriedade, nos termos seguintes:

${ }^{7} \S 16$. É garantido o direito de propriedade, salvo o caso de desapropriação por necessidade ou utilidade pública, ou por interêsse social, mediante prévia e justa indenização em dinheiro, com a exceção prevista no $\S 1^{\circ}$ do art. 147. Em caso de perigo iminente, como guerra ou comoção intestina, as autoridades competentes poderão usar da propriedade particular, se assim o exigir o bem público, ficando, todavia, assegurado o direito a indenização ulterior (BRASIL, 1946).

${ }^{8}$ Cria o Programa de Integração Nacional, altera a legislação do imposto de renda das pessoas jurídicas na parte referente a incentivos fiscais e dá outras providências.

${ }^{9}$ Institui o Programa de Redistribuição de Terras e de Estímulo à Agro-indústria do Norte e do Nordeste (PROTERRA), altera a legislação do imposto de renda relativa a incentivos fiscais e dá outras providências.
} 
grande contingente de pessoas que migraram para a região amazônica, incentivados pela facilidade de aquisição de terras e trabalho em virtude do milagre econômico brasileiro (MAGALHÃES, 2002).

De acordo com Magalhães, O II Plano Nacional de Desenvolvimento, aprovado pela Lei 6.151 de dezembro de 1974, estabeleceu mudança de estratégia desenvolvimentista e adotou medidas de caráter conservacionista, estabelecendo uma política alinhada com paradigmas do direito ambiental discutida internacionalmente (MAGALHÃES, 2002).

Segundo o referido autor, o modelo proposto pelo II Plano Nacional de Desenvolvimento, trouxe inúmeros benefícios para a política ambiental brasileira, maximizando a criação diplomas legais que contribuíram para o fortalecimento da proteção dos recursos naturais, dentre as quais destacam-se: a) Lei 6.225 , de 14 de julho de $1975^{10}$; b) Decreto $\mathrm{n}^{\circ} 76.470$, de 16 de outubro de $1975^{11}$; c) Decreto $\mathrm{n}^{\mathrm{o}} 1.413$, de 14 de agosto de $1975^{12}$; d) Lei $\mathrm{n}^{\mathrm{o}} 6.766$, de 19 de dezembro de $1979^{13}$; e) Lei $n^{\circ} 6.902$, de 27 de abril de $1981^{14}$; f) Lei $n^{\circ} 6.803$, de 2 de junho de $1980^{15}$; g) Decreto 73.030 , de 30 de outubro de $1973^{16}$.

Apesar do caráter desenvolvimentista adotado pelo Estado durante o regime militar, houve evolução na legislação ambiental, com a redefinição de competências da matéria, bem como a imposição de controle legal às atividades exploratórias dos recursos naturais pela iniciativa econômica.

A Aprovação do III Plano Nacional de Desenvolvimento, em 5 de dezembro de 1979, representou verdadeira consolidação do Direito Ambiental no Brasil, promovendo discussão de políticas ambientais de alcance nacional. (MAGALHÃES, 2002). Ademais, de acordo com o item II do capítulo VI do referido Plano (III PND), a partir de então:

A ênfase na preservação do patrimônio público, artístico, cultural e dos recursos naturais do Brasil, bem como na prevenção, controle e combate da poluição em todas as suas formas estará presente em todos os desdobramentos da política nacional de desenvolvimento e na sua execução (BRASIL, 1980, p. 92).

Da leitura supramencionada, compreende-se que o novo modelo proposto pelo III PND estabeleceu princípios e objetivos bem definidos, que contribuíram para o fortalecimento das políticas voltadas ao meio ambiente. Neste cenário foram criados órgãos órgão como o Conselho Nacional do Meio Ambiente - CONAMA e o Sistema Nacional do Meio Ambiente - SISNAMA, bem como instituídos instrumentos para a garantia da preservação ambiental, tais como, o controle

\footnotetext{
${ }^{10}$ Dispõe sobre discriminação, pelo Ministério da Agricultura, de regiões para execução obrigatória de planos de proteção ao solo e de combate à erosão e dá outras providências;

${ }^{11}$ Cria o Plano Nacional de Conservação dos Solos.

${ }^{12}$ Dispõe sobre o controle da poluição do meio ambiente provocada por atividades industriais

${ }^{13}$ Dispõe sobre o parcelamento do solo.

${ }^{14}$ Cria as chamadas estações ecológicas e Áreas de proteção ambiental.

${ }^{15}$ Estabelece diretrizes básicas para o zoneamento industrial das Áreas críticas de poluição.

${ }^{16}$ Criação da Secretaria Especial do Meio Ambiente - SEMA.
} 
da poluição, o zoneamento ambiental, a avaliação de impactos ambientais, a responsabilização objetiva para poluidores, a legitimidade para o Ministério Público propor Ação Civil Pública entre outros. (MAGALHÃES, 2002).

O III PDN, portanto, exerceu influência direta na profusão da legislação ambiental brasileira e seus reflexos podem ser observados no contexto histórico das legislações ${ }^{17}$ ordinárias da época no que se refere à proteção ao meio ambiente, refletindo seus princípios, objetivos e instrumentos em todas as decisões políticas, e na aprovação da Lei 7.486, de 1986, que dedicou um capítulo especial à Polícia Ambiental, consolidando o Direito Ambiental.

Conforme Magalhães (2002) a promulgação da Constituição Federal de 1988, inaugurou um período de aperfeiçoamento do Direito Ambiental. Um capítulo inteiro do texto constitucional foi dedicado à proteção do Meio Ambiente, posicionando o Brasil em destaque, em virtude das mudanças significativas e da grande repercussão política, ecológica, social e econômica de seu novo texto constitucional.

O artigo 23, em seus incisos III, VI e VII da nova Constituição estabeleceu que a competência para "proteger os documentos, as obras e outros bens de valor histórico, artístico e cultural, os monumentos, as paisagens naturais notáveis e os sítios arqueológicos"; "proteger o meio ambiente e combater a poluição em qualquer de suas formas", além de "preservar as florestas, a fauna e a flora” é comum à União, Estados, Distrito Federal e Municípios, criando uma espécie de "federalismo cooperativo" em matéria ambiental (BRASIL, [2019]).

Dessa forma, o constituinte originário, visando garantir a efetiva proteção do Meio Ambiente, a execução das diretrizes, políticas e preceitos relativos à proteção ambiental, estabeleceu no parágrafo único do artigo 23 da $\mathrm{CRFB} / 88$, que "leis complementares fixarão normas para a cooperação entre a União e os Estados, o Distrito Federal e os Municípios, tendo em vista o equilíbrio do desenvolvimento e do bem-estar em âmbito nacional." (BRASIL, [2019]). Infere-se, desta forma, que a competência em matéria ambiental é comum a todos os entes políticos e repartida para realização de tarefas em forma cooperada. (THOMÉ, 2014, p. 136).

Nessa lógica, a Lei Complementar 140/2011 representa um marco regulatório para várias temáticas do setor ambiental por estabelecer diretrizes para a descentralização da gestão, de forma qualificada e com transparência de informações para melhor conservação do meio ambiente natural.

\footnotetext{
${ }^{17}$ Decreto n. 84.464, de 7 de fevereiro de 1980 - Dispõe sobre a criação do Grupo de Trabalho para revisão e reformulação da Legislação Florestal;

*Lei n. 6.902, de 27 de abril de 1981 - Dispõe sobre a criação de Estações Ecológicas, Áreas de Proteção Ambiental; *Lei n. 6.902, de 27 de abril de 1981 - Dispõe sobre as diretrizes básicas para o zoneamento industrial nas Áreas críticas de poluição;

*Lei n. 6.938, de 31 de agosto de 1981 - Dispõe sobre a Política Nacional do Meio Ambiente, seus fins e mecanismos de formulação e aplicação.
} 
De acordo com Benjamin, tal momento foi "o ápice que simboliza a consolidação dogmática e cultural de uma visão jurídica de mundo", sepultando, portanto, o paradigma liberal e saltando para um estágio de opulência ecológico constitucional. (BENJAMIN, 2012, p. 90).

Neste contexto, implantou-se o Programa Nossa Natureza, um dos mais importantes programas de preservação ecológica, cujos objetivos foram: a) conter a ação antrópica sobre o meio ambiente e os recursos naturais renováveis; b) estruturar o sistema de proteção ambiental; c) desenvolver a educação ambiental e a conscientização pública para a conservação da natureza; d) disciplinar a ocupação e a exploração da Amazônia, com base no ordenamento territorial; e) regenerar o complexo de ecossistemas afetados pela ação antrópica; f) proteger as comunidades indígenas e as populações envolvidas no processo de extrativismo.

O advento do Decreto ${ }^{\circ} 96.944$, de 12 de outubro de $1988^{18}$, promoveu a correção de falhas tanto na legislação florestal, quanto na Lei de Política Nacional do Meio Ambiente, além dos incentivos fiscais para a Amazônia. Assim, reestruturou-se a administração ambiental e criouse a Secretaria do Meio Ambiente, com status de Ministério.

Contribuindo para o aperfeiçoamento do Direito Ambiental no Brasil, a cidade do Rio de Janeiro sediou, no ano de 1992, a Conferência das Nações Unidas sobre Meio Ambiente e Desenvolvimento, conhecida como ECO-92. Tal evento teve repercussão mundial, pois conseguiu reunir mais de $80 \%$ dos países do mundo para buscar o mesmo objetivo - a defesa do meio ambiente (MAGALHÃES, 2002).

A ECO-92 foi um evento de extrema relevância para a consolidação do Direito Ambiental, o que pode ser observado pelos cinco documentos produzidos neste evento, quais sejam: a) Declaração do Rio de Janeiro; ${ }^{19}$ b) Declaração de Princípios sobre Florestas; ${ }^{20}$ c) Convenção sobre a Biodiversidade; ${ }^{21}$ d) Convenção sobre o clima; $; 2$ e) Agenda $21 .{ }^{23}$

Por seu turno a ecologização constitucional demandou mudanças e transformações no Estado e no Direito, dessa forma, o movimento verde da década de 1970 inaugurou um novo momento na história da tutela dos bens ambientais, uma vez que promoveu mudanças paradigmáticas no que se refere ao alcance da proteção ambiental influenciando diretamente na construção do texto da Constituição Federal de 1988.

\footnotetext{
${ }^{18}$ Cria o Programa de Defesa do Complexo de Ecossistemas da Amazônia Legal e dá outras providências com a finalidade de estabelecer condições para a utilização e a preservação do meio ambiente e dos recursos naturais renováveis na Amazônia Legal, mediante a concentração de esforços de todos os órgãos governamentais e a cooperação dos demais segmentos da sociedade com atuação na preservação do meio ambiente.

${ }^{19}$ Cumula 27 princípios ambientais e orienta a implantação do desenvolvimento sustentável na Terra, também conhecida como Carta da Terra.

${ }^{20}$ Estabelece a proteção florestal nos variados tipos de florestas.

${ }^{21} 112$ países comprometeram-se em proteger as riquezas biológicas

${ }^{22}$ Estabelece o convencionado por 152 países acerca da preservação do equilíbrio atmosférico, principalmente o controle de emissão do $\mathrm{CO}^{2}$.

${ }^{23} \mathrm{Um}$ guia de cooperação internacional, que propõe instrumentos de planejamento participativo visando o desenvolvimento sustentável.
} 
A partir de então, o Meio Ambiente passou a ser reconhecido como direito constitucional, pois sua violação contempla riscos que compreendem a insegurança política, jurídica e social, destacando-se pela rápida trajetória de transformação e incorporação no direito, passando de um status quase nada jurídico e chegando ao ápice da hierarquia normativa, alcançando inclusive pactos políticos transnacionais.

Nas palavras de Soares, o Direito ambiental de forma integrada surgiu em virtude da necessidade proveniente de fenômenos que a própria sociedade concebeu e que resultaram na desolação das relações harmônicas entre o homem e seu meio circundante. (SOARES, 2011, p. $65)$.

Por conseguinte, o Direito Ambiental surge como "um meio para estabelecer regras de comportamento, obrigações de fazer e não fazer, de modo a salvaguardar um direito fundamental que cumpre a função de integrar direitos à saudável qualidade de vida, ao desenvolvimento econômico e à proteção dos recursos naturais". (ANTUNES, 2002, p.8).

Percebe-se uma clara alteração de paradigmas: o modelo de proteção estritamente florestal é substituído por um modelo baseado na sustentabilidade dos recursos naturais, conforme será demonstrado adiante.

\section{Mudança de paradigmas: do Direito Florestal ao Direito Ambiental}

A reconstrução da evolução da proteção jurídica do Meio Ambiente permite inferir que as transformações ocorridas no Brasil tanto no que diz respeito ao transcurso do período colonial para Império e posteriormente para a República, quanto aos regimes democráticos e seus diferentes ciclos econômicos acompanharam as mutações na tutela dos bens ambientais. (BENJAMIN, 2015).

Da mesma maneira, gradualmente ganhou ênfase a percepção de intelectuais, políticos, organizações não governamentais, entre tantos atores sociais, acerca da necessidade de práticas transformadoras e a adoção de meios garantidores do desenvolvimento sustentável, desconstruindo a ideia de algo abstrato e regressivo, passando a ser reconhecido pela comunidade mundial como o maior desafio da atualidade.

Nesse contexto, a Lei 9.638, de 31 de agosto de 1981, que instituiu a Política Nacional do Meio Ambiente (PNMA), inspirada nos princípios norteadores da Conferência das Nações Unidas sobre o Meio ambiente Humano, realizada em Estocolmo em 1972, inaugurou um processo de ecologização do sistema jurídico brasileiro, traçando um modelo normativo que conciliava economia e sustentabilidade, o que ficou conhecido como eclosão ecologista. (BENJAMIN, 2015).

No entanto, o ápice da expressão de sensibilidade ecológica no constitucionalismo brasileiro, concretizou-se com a promulgação da Constituição Republicana de 1988, que no seu artigo 225, caput, estabeleceu "o direito de todos ao meio ambiente ecologicamente equilibrado, 
bem de uso comum do povo e essencial à sadia qualidade de vida, impondo-se ao Poder Público e à coletividade o dever de defendê-lo e preservá-lo para as presentes e futuras gerações" (BRASIL, [2019]).

Observando a tendência mundial, o Brasil inovou o tratamento da questão ambiental em sua atual Carta Política, dedicando um capítulo à matéria, com isso, o Meio Ambiente deixou de ser visto como um direito individual e alcançou status social, interessando a toda a coletividade. Assim, reconhecido o seu caráter fundamental, inclui-se o direito ao meio ambiente ecologicamente equilibrado no rol das cláusulas pétreas, incorporando-se ao conjunto de direitos estritamente resguardados. Dessa forma, pode-se afirmar, segundo José Afonso da Silva, que "o capítulo do meio ambiente é um dos mais importantes e avançados da Constituição de 1988" (SILVA, 2005, p. 845).

Nesse contexto, a Constituição Federal de 1988 representa um marco no ordenamento jurídico ambiental brasileiro, caracterizando-se como inovadora quando comparada às demais legislações ambientais por se revestir de unicidade no trato da matéria, antes marcada pela fragmentariedade dos elementos. Desde então, o Estado passou a organizar-se na forma de uma ordem pública ambiental constitucionalizada. (BENJAMIN, 2012).

Tal proteção estendeu-se desde a preservação da natureza e seus elementos essenciais à vida humana, tais como ar, água, flora, fauna, vegetação, resíduos sólidos entre outros, até a manutenção desses recursos para a garantia de um meio ambiente sadio e ecologicamente equilibrado, de uso comum do povo e essencial à qualidade de vida, havendo necessidade de protegê-lo e preservá-lo para as presentes e futuras gerações, estabelecendo assim o que se definiu como direito intergeracional. Traduziu a Constituição Federal de 1988 em vários dispositivos o que pode ser considerado um dos "sistemas mais abrangentes e atuais do mundo sobre a tutela do meio ambiente" (MILARÉ, 2013, p.168).

Neste cenário, gradativamente surgiram as primeiras legislações com cunho protecionista aos bens naturais, consubstanciando-se com as Constituições Estaduais, Leis Orgânicas, somando-se aos novos e diversos diplomas oriundos de todos os níveis de Poder Público e hierarquia normativa, voltados à proteção do desfalcado patrimônio natural do país. Sendo assim, discute-se a proposta de um novo paradigma de Estado, o qual se desvincula da visão antropocêntrica, onde o homem é o centro do universo, a referência máxima e absoluta do Estado e do Direito e estatui o meio ambiente como indispensável para a manutenção da vida no globo em uma relação de mutualismo com o homem, com foco voltado para a vida e todos os aspectos que ela envolve.

O Estado de Direito Ambiental surge então com um iminente desafio: estabelecer o biocentrismo em um contexto de riscos globais que só cresce continuamente, principalmente a partir do instante em que se identifica o meio ambiente sadio e equilibrado como condição sine qua non para vida em geral. O Estado de Direito Ambiental apresenta-se, como a forma jurídica 
de realização do projeto constitucional de garantia de direitos fundamentais, dentre os quais inclui-se de forma especial o ambiental.

Considerando que o Direito não opera no vazio, mas se redefine em função de mudanças na própria sociedade, McNeill (2011) revela a emergência de um Estado de Direito Socioambiental e considera o século XX como o século do ambientalismo. Desta forma, a história ambiental seria o principal legado do século XX.

Para Barros (2013) isso decorre da construção social do socioambientalismo como um metarrelato político, que se justifica pela sua natureza discursiva complexa e seu caráter de interdisciplina, caracterizando-o como um campo de poder cada vez mais estruturado, organizado e centralizado. Segundo o autor, tal construção se deu a partir de concepções e saberes produzidos por múltiplos atores e discursos políticos, sejam estes de movimentos sociais, entidades científicas, partidos políticos, ambientalistas ou instituições estatais, e em virtude destas tais discussões não devem ser compreendidas como uma produção independente.

O autor destaca que além da pluralidade de atores, o debate público passou a promover a incorporação de diferentes fatores relacionados a temática ambiental, tais como: fatores naturais, políticos, econômicos, culturais, ideológicos. Dessa forma, se caracteriza como um discurso condicionado por múltiplos fatores e atores sociais, culturais e políticos, com suas diversidades em termos de lógicas de ação e de reação.

Nesse sentido, Morin (1994) considera o ambientalismo como parte do pensamento complexo que passou a caracterizar o debate científico contemporâneo, uma vez que a crise ambiental afeta também a razão, o pensamento social, o conhecimento político, as práticas culturais e o comportamento humano. Além de necessitar de contribuições de diversas áreas científicas.

Corroborando, Leff (2009) refere-se ao ambientalismo como articulador de uma nova racionalidade uma vez que esse campo de conhecimento reúne e integraliza saberes de diversos outros campos, tanto teóricos como normativos e práticos. Esse diálogo estimula atores sociais a participarem da elaboração de estratégias alternativas de reapropriação da natureza em um campo conflitivo de poder, do qual se desdobram sentidos diferenciados e, muitas vezes, antagônicos, na construção de um futuro sustentável.

Destarte, um Estado de Direito, além de ser constitucional e democrático, deve ser também um Estado de Direito Ambiental, incorporando novos elementos, como a globalização, o desenvolvimento tecnocientífico e os direitos relativos ao desenvolvimento e assim atendendo às demandas sociais e se adequando à evolução da sociedade.

Contudo, para a real consecução de um Estado Democrático de Direito, não basta que normas constitucionais protejam a autonomia do indivíduo perante o poder do estado, é de suma importância a garantia de seus direitos e liberdades. Nesse sentido, trata-se de uma obra inacabada, com conceito não pronto, assim é na verdade, "um processo de constante atualização 
e aperfeiçoamento. É um conceito dinâmico que, ao incorporar novos elementos e novos conceitos, modifica a sua própria estrutura e racionalidade" (TARREGA; SANTOS NETO, 2006, p. 9).

Assim, o Estado de Direito Ambiental "é um processo político-legal de esverdeamento do Estado, marcado por uma constante atualização, aperfeiçoamento e incorporação de novos elementos que modificam a sua própria estrutura e racionalidade tradicionais". (LEITE; CAETANO, 2012, p. 53). Dessa forma incorpora o meio ambiente como um direito fundamental no direito brasileiro, redefinindo a concepção de Estado a partir do reconhecimento de novos direitos e reinterpretação dos direitos anteriormente reconhecidos.

Para a definição objetiva de Estado de Direito Ambiental, Leite e Belchior (2012, p. 19) afirmam que o mesmo "pode ser compreendido como produto das novas reivindicações fundamentais do ser humano e particularizado pela ênfase que confere à proteção do meio ambiente." Oportuno ressaltar que esse novo modelo de Estado, construído a partir da Constituição Federal de 1988, é dotado de princípios estruturantes próprios, que unidos formam a fundamentação teórico-jurídico do Estado de Direito Ambiental.

Assim, o Estado de Direito Ambiental, não importa o surgimento de outro Estado, mas o fortalecimento perspectivas baseadas numa consciência ecológica, onde tanto o Poder Público quanto a coletividade possam lançar mão de diferentes instrumentos, metas e atividades de forma integrada, preventiva, precaucional e solidária, que sejam capazes de administrar adequadamente os riscos ambientais que surgem com a modernidade avançada.

\section{Considerações finais}

O presente trabalho questionou acerca das condições e possibilidades da proteção jurídico-constitucional do Meio Ambiente em um modelo de desenvolvimento capaz ao mesmo tempo de considerar as gerações futuras e de garantir a sustentabilidade dos recursos naturais. A reposta provisória dada inicialmente a este questionamento repousou no reconhecimento de um novo modelo paradigmático de Estado, o de Direito Ambiental.

A partir da reconstrução da evolução da proteção jurídica do Meio Ambiente, realizada com base na reconstrução de diversos ordenamentos jurídicos de estados estrangeiros, com vistas à realização de uma análise jurídico comparativa, verifica-se que o modelo inicialmente adotado possuía uma perspectiva protecionista das florestas ainda que restrita à esfera penal, sendo possível inferir que desde as primeiras civilizações o homem busca meios de proteção do meio ambiente, ainda que incipiente.

Percorrendo a evolução da legislação florestal brasileira, notou-se que tal proteção permeou os períodos colonial, imperial, assim como o republicano da nossa história. Este último influenciado pela eclosão ecológica da década de 1970, promoveu expansão do objeto de proteção 
do Direito florestal promovendo verdadeira mudança de paradigmas, uma vez que alcançou novos objetos de tutela, saindo de um modelo florestal instituindo a ideia do meio ambiente global e assim exercendo influência na Constituição Federal de 1988.

A Constituição Federal de 1988, ao dedicar um capítulo específico ao meio ambiente, revelou seu comprometimento com a preservação da natureza e seus bens essenciais à vida humana, tais como ar, água, flora, vegetação, resíduos sólidos entre outros, assim como, um meio ambiente sadio e ecologicamente equilibrado para as presentes e futuras gerações.

Assim, com o entendimento da história da proteção ambiental e dos princípios norteadores da ecologização constitucional, além do reconhecimento dos riscos da atualidade, o Direito Ambiental viabiliza a efetiva utilização de seus instrumentos como forma de salvaguardar o Meio Ambiente. Surge, assim uma dimensão da segurança jurídica ambiental afim de efetivar a justiça ambiental pautada na solidariedade intergeracional.

O Estado de Direito Ambiental, ao fundar a lógica biocentrista, apresenta-se como a forma jurídica de realização do projeto constitucional de garantia dos direitos fundamentais, dentre os quais destaca-se o direito ao meio ambiente ecologicamente equilibrado, permitindo concluir o presente trabalho pela confirmação da hipótese inicialmente apresentada.

\section{REFERÊNCIAS}

AHRENS, Sérgio. O "Novo" Código Florestal Brasileiro: Conceitos Jurídicos Fundamentais. In: CONGRESSO FLORESTAL BRASILEIRO, 8. 2003, São Paulo. Anais [...]. São Paulo: Sociedade Brasileira de Silvicultura, 2003. p. 1-15. Disponível em: https://ainfo.cnptia.embrapa.br/digital/bitstream/item/60219/1/SP4708.pdf. Acessado em: 5 jun. 2018

ANTUNES, Paulo de Bessa. Direito Ambiental. Rio de Janeiro: Editora Lumen Juris, 2002

BARROS, Antônio Teixeira de. O ambientalismo como interdisciplina sociocultural e pensamento complexo. Perspectivas, Araraquara, v. 44, p. 63-91, jul./dez. 2013. Disponível em: https://periodicos.fclar.unesp.br/perspectivas/article/view/7403. Acesso em: 5 jun. 2018.

BRASIL. [Constituição (1824)]. Constituição Política do Império do Brazil. Coletânea das Leis do Império do Brasil de 1824. Rio de Janeiro, 25 mar. 1824. Disponível em: http://www.planalto.gov.br/ccivil_03/constituicao/constituicao24.htm. Acesso em: 5 jun. 2018.

BRASIL. [Constituição (1891)]. Constituiçãa da Republica dos Estados Unidos do Brasil. Diário Oficial da República dos Estados Unidos do Brasil. Rio de Janeiro, 24 fev. 1891. Disponível em: http://www.planalto.gov.br/ccivil_03/constituicao/Constituicao91.htm. Acesso em: 5 jun. 2018.

BRASIL. [Constituição (1934)]. Constituiçãa da Republica dos Estados Unidos do Brasil. Diário Oficial da União. Rio de Janeiro, 16 jul. 1934. Disponível em: http://www.planalto.gov.br/ccivil_03/constituicao/constituicao34.htm. Acesso em: 5 jun. 2018. 
BRASIL. [Constituição (1937)]. Constituiçãa da Republica dos Estados Unidos do Brasil. Diário Oficial da União. Rio de Janeiro, 10 nov. 1937. Disponível em:

http://www.planalto.gov.br/ccivil_03/Constituicao/Constituicao37.htm. Acesso em: 5 jun. 2018.

BRASIL. [Constituição (1946)]. Constituição da Republica dos Estados Unidos do Brasil. Diário Oficial da União. Rio de Janeiro, 18 set. 1946. Disponível em: http://www.planalto.gov.br/ccivil_03/Constituicao/Constituicao46.htm. Acesso em: 5 jun. 2018.

BRASIL. [Constituição (1967)]. Constituiçãa da Republica Federativa do Brasil. Diário Oficial da União. Brasília, 24 jan. 1967a. Disponível em:

http://www.planalto.gov.br/ccivil_03/Constituicao/Constituicao67.htm. Acesso em: 5 jun. 2018.

BRASIL. [Constituição (1967)]. Emenda Constitucional no 1, de 17 de outubro de 1969. Diário Oficial da União, Brasília, 20 out. 1969. Disponível em:

http://www.planalto.gov.br/ccivil_03/Constituicao/Constituicao67EMC69.htm. Acesso em: 5 jun. 2018.

BRASIL. [Constituição (1988)]. Constituição da República Federativa do Brasil. Brasília: Presidência da República, [2019]. Disponível em:

http://www.planalto.gov.br/ccivil_03/Constituicao/constituicaocompilado.htm. Acesso em: 5 jun. 2018.

BRASIL. Decreto $\mathbf{n}^{0}$ 23.793, de 23 de janeiro de 1934. Aprova o Código florestal que com esta baixa. Rio de Janeiro, 1934. Disponível em:

http://www.planalto.gov.br/ccivil_03/decreto/1930-1949/D23793.htm. Acesso em: 25 fev. 2017.

BRASIL. Decreto $\mathbf{n}^{0}$ 289, de 28 de fevereiro de 1967. Cria o Instituto Brasileiro do Desenvolvimento Florestal e dá outras providências. Brasília: Presidência da República, 1967. Disponível em: http://www.planalto.gov.br/ccivil_03/decreto-lei/1965-1988/Del0289.htm. Acesso em: 5 jun. 2018.

BRASIL. Decreto no 4.421, de 28 de dezembro de 1921. Crêa o Serviço Florestal do Brasil. Rio de Janeiro, 1921. Disponível em: http://www2.camara.leg.br/legin/fed/decret/19201929/decreto-4421-28-dezembro-1921-567912-publicacaooriginal-91264-pl.html. Acesso em: 5 jun. 2018.

BRASIL. Decreto $\mathbf{n}^{0}$ 17.042, de 16 de setembro de 1925. Dá regulamento ao Serviço Florestal do Brasil. Rio de Janeiro, 1925. Disponível em:

http://www2.camara.leg.br/legin/fed/decret/1920-1929/decreto-17042-16-setembro-1925507806-publicacaooriginal-1-pe.html. Acesso em: 5 jun. 2018.

BRASIL. Lei $\mathbf{n}^{\mathbf{0}} \mathbf{7 . 7 3 5}$, de 22 de fevereiro de 1989. Dispõe sobre a extinção de órgão e de entidade autárquica, cria o Instituto Brasileiro do Meio Ambiente e dos Recursos Naturais Renováveis e dá outras providências. Brasília: Presidência da República, 1989. Disponível em: http://www.planalto.gov.br/ccivil_03/LEIS/L7735.htm. Acesso em: 5 jun. 2018. 
BRASIL. III Plano Nacional de Desenvolvimento - 1980/85. Brasília, 1980.

BENJAMIN, Antônio Herman. Constitucionalização do Ambiente e Ecologização da Constitucionalização Brasileira. In: CANOTILHO, José Joaquim Gomes; LEITE, José Rubens Morato (org.). Direito Constitucional Ambiental Brasileiro. São Paulo: Saraiva, 2012.

CARNEIRO, Raissa Orestes. Novo Código Florestal Brasileiro: A construção da legislação sobre florestas no Brasil. Revista do departamento de história da Universidade Federal de Pernambuco, Recife, v. 8, n. 8, 2011.

DEAN, Warren. A ferro e fogo: a história e a devastação da Mata Atlântica brasileira. 1. ed. São Paulo: Cia. das Letras, 2006.

DUBY, Georges. Guerreiros e camponeses. Lisboa: Estampa, 1993.

LEFF, Enrique. Complexidade, racionalidade ambiental e diálogo de saberes. Educação \& Realidade, Porto Alegre, v. 34, n. 3, p.17-24, set./dez. 2009.

LEITE, José Rubens Morato; BELCHIOR, Germana Parente Neiva. Dano ambiental na sociedade de risco: uma visão introdutória. In: LEITE, José Rubens Morato; FERREIRA, Heline Sivini; FERREIRA, Maria Leonor Paes Cavalcanti (Org.). Dano Ambiental na sociedade de risco. São Paulo: Saraiva, 2012.

LEITE, José Rubens Morato; CAETANO, Matheus Almeida. Breves reflexões sobre elementos do Estado de Direito Ambiental Brasileiro. In: LEITE, José Rubens Morato; FERREIRA, Heline Sivini; CAETANO, Matheus Almeida (Org.). Repensando o Estado de Direito Ambiental. Florianópolis: Fundação Boiteux, 2012.

MAGALHÃES, Juarez Peres. Evolução do direito ambiental brasileiro. 12. ed. São Paulo: Editora Juarez de Oliveira, 2002.

MCNEILL, J. R. Something new under the sun: An environmental history of the twentiethcentury world (the global century series). NewYork; London: Norton \& Company, 2011.

MILARÉ, Édis. Direito Ambiental. 8. ed. São Paulo: Editora Revista dos Tribunais, 2013.

MORIN, E. Introducción al pensamento complejo. Barcelona: Gedisa, 1994

PEREIRA, Osny Duarte. Direito florestal brasileiro. Rio de Janeiro: Borsoi, 1950.

SILVA, José Afonso da. Curso de Direito Ambiental Positivo. 25 ed. São Paulo: Malheiros, 2005.

VENOSA, Silvio de Salva. Direito Civil: Parte Geral. 17. ed. São Paulo: Editora Atlas, 2016. 704 p. v. 1.

TARREGA, Maria Cristina Vidotte Blanco; SANTOS NETO, Arnaldo Bastos. Novo Paradigma interpretativo para a Constituição brasileira: The Green WelfareState. In: CONGRESSO

NACIONAL DO CONSELHO NACIONAL DE PESQUISA E PÓS-GRADUAÇÃO EM DIREITO, 15. 2006, Manaus. Anais [...]. Manaus: CONPEDI, 2006. p. 1-19. Disponível em: http://www.publicadireito.com.br/conpedi/manaus/arquivos/anais/manaus/direito_racion_democ _maria_c_tarrega_e_arnaldo_santos_neto.pdf. Acesso em: 5 jun. 2018.

THOMÉ, Romeu. Manual de Direito Ambiental. 4. ed. Salvador: Editora Juspodivm, 2014. 
SOARES, Guido Fernando Silva. Curso de Direito Internacional Público. São Paulo: Atlas, 2011.

Artigo submetido em: 2018-09-06

Artigo reapresentado em: 2018-11-30

Aceito em: 2019-04-09 